\title{
Evaluation of Antioxidant, Antidiabetic and Anticholinesterase Activities of Smallanthus sonchifolius Landraces and Correlation with Their Phytochemical Profiles
}

\author{
Daniela Russo $^{1, *}$, Patrícia Valentão ${ }^{2}$, Paula B. Andrade ${ }^{2}$, Eloy C. Fernandez ${ }^{3}$ and Luigi Milella ${ }^{1, *}$ \\ 1 Department of Science, Basilicata University, 85100 Potenza, Italy \\ 2 Rede de Química e Tecnologia/Laboratório Associado para a Química Verde (REQUIMTE/LAQV), \\ Laboratório de Farmacognosia, Departamento de Química, Faculdade de Farmácia, \\ Universidade do Porto, 4050-313 Porto, Portugal; E-Mails: valentao@ff.up.pt (P.V.); \\ pandrade@ff.up.pt (P.B.A.) \\ 3 Department of Crop Sciences and Agroforestry, Faculty of Tropical AgriSciences, \\ Czech University of Life Sciences, 16521 Prague, Czech Republic; E-Mail: fernandez@ftz.czu.cz \\ * Authors to whom correspondence should be addressed; \\ E-Mails: daniela.russo@unibas.it (D.R.); luigi.milella@unibas.it (L.M.); \\ Tel.: +39-0971-205-531 (D.R.); +39-0971-205-525 (L.M.); \\ Fax: +39-0971-205-503 (L.M.).
}

Academic Editor: Chang Won Choi

Received: 19 May 2015 / Accepted: 28 July 2015 / Published: 31 July 2015

\begin{abstract}
The present study aimed to investigate the phytochemical profile of leaf methanol extracts of fourteen Smallanthus sonchifolius (yacon) landraces and their antioxidant, anticholinesterase and antidiabetic activities that could lead to the finding of more effective agents for the treatment and management of Alzheimer's disease and diabetes. For this purpose, antioxidant activity was assessed using different tests: ferric reducing ability power (FRAP), 2,2-diphenyl-1-picryl hydrazyl (DPPH), nitric oxide ( $\mathrm{NO}$ ) and superoxide $\left(\mathrm{O}_{2}{ }^{-}\right)$scavenging and lipid peroxidation inhibition assays. Anticholinesterase activity was investigated by quantifying the acetylcholinesterase (AChE) and butyrylcholinesterase (BChE) inhibitory activities, whereas antidiabetic activity was investigated by $\alpha$-amylase and $\alpha$-glucosidase inhibition tests. To understand the contribution of metabolites, phytochemical screening was also performed by high performance liquid chromatography-diode array detector (HPLC-DAD) system. Among all, methanol extract of PER09, PER04 and ECU44 landraces exhibited the highest relative
\end{abstract}


antioxidant capacity index (RACI). ECU44 was found to be rich in 4,5-di- $O$-caffeoylquinic acid (CQA) and 3,5-di- $O$-CQA and displayed a good $\alpha$-amylase and $\alpha$-glucosidase inhibition, showing the lowest $\mathrm{IC}_{50}$ values. Flavonoids, instead, seem to be involved in the $\mathrm{AChE}$ and $\mathrm{BChE}$ inhibition. The results of this study revealed that the bioactive compound content differences could be determinant for the medicinal properties of this plant especially for antioxidant and antidiabetic activities.

Keywords: Smallanthus sonchifolius; phytochemical profile; antioxidant activity; anti-cholinesterase activity; anti-diabetic activity

\section{Introduction}

Medicinal plants, as source of remedies, are widely used as alternative therapeutic tools for the prevention or treatment of many diseases. Recently, great attention has been devoted to the use of natural compounds, due to their nutritional and pharmacological characteristics.

Smallanthus sonchifolius (Poepp. \& Hendl.) H. Robinson, commonly called yacon, belongs to the Asteraceae family. It is a tuberous plant native to the Andes, but it has been introduced in Japan, New Zealand, Europe (primarily in Czech Republic) and United States [1]. Yacon is a perennial herb with large dark green leaves and two types of underground portions: edible tuberous roots, used by the plant for food storage, and fibrous roots used for vegetative reproduction. Each plant produces 4 to 20 edible tubers that can reach $20 \mathrm{~kg}$ [2]. Andean indigenous people have always used yacon as an important crop: they have used it not only for its edible tuberous roots, but also as a vegetable and medicinal plant. Roots of yacon can contain high amounts ( $40 \%-70 \%$ dry weight) of fructooligosaccharides $[3,4]$ that are not metabolized in the human digestive tract and hence their consumption does not enhance the level of glucose in the blood. In addition, studies have reported that extracts of leaves reduce glycemia in the plasma of diabetic rats [5] and some constituents of yacon leaves inhibit the $\alpha$-glucosidase enzyme involved in the diabetes [6]. For this reason yacon is considered to be a food and a remedy with a high potential for diabetics. The low energy value of its tuberous roots makes yacon an ideal foodstuff for people suffering from obesity. Leaves are also a rich source of antioxidants [7] and several studies showed that this part of the plant possesses different biological effects, like inhibition of migration of polymorphonuclear leucocytes [8], immunomodulation [9], antioxidant, cytoprotection effects [10-12] and antimicrobical activity [13].

The search for the bioactive compounds from medicinal plants is always an alternative mean of finding new drugs. Phytochemical screening of $S$. sonchifolius will lead to the rationalization of the use of this plant in various diseases and could also lead to the finding of more effective agents that have effective treatment roles against specific diseases. Alzheimer's disease (AD) was firstly described in 1906 by Alois Alzheimer, a Bavarian neuropsychiatrist [14]. AD is a progressive neurodegenerative disorder of the elderly, characterized by widespread loss of central cholinergic function. The only symptomatic treatment proven effective to date is the use of cholinesterase $(\mathrm{ChE})$ inhibitors to augment surviving cholinergic activity. ChE inhibitors act on the enzymes that hydrolyze acetylcholine (ACh) following synaptic release. In the healthy brain, acetylcholinesterase (AChE) predominates 
$(80 \%)$ and butyrylcholinesterase $(\mathrm{BChE})$ is considered to play a minor role in regulating brain $\mathrm{ACh}$ levels. Therefore both enzymes are likely to have involvement in regulating ACh levels and represent legitimate therapeutic targets to ameliorate the cholinergic deficit. Many plants have been studied by different approaches for the identification of new AChE inhibitors (AChE-Is) and different classes of plant-derived natural products have been considered as new AChE-Is potentially useful for AD treatment. Both non-alkaloids and alkaloid-derivative compounds [15] have been studied.

The incidence of diabetes mellitus in the world is increasing at an alarming rate, affecting close to $5 \%$ of its population and it is strictly related to several other diseases [16,17]. Diabetes mellitus is a complex disease characterized by gross derangement in carbohydrate, fat and protein metabolism, due to deficiency in insulin secretion and/or action [18]. Mammalian $\alpha$-amylase is a prominent enzyme in the pancreatic juice, breaking down large and insoluble starch molecules into absorbable molecules, ultimately maltose [19]. $\alpha$-Glucosidase, on the other hand, anchored in the mucosal brush border of the small intestine, catalyzes the end step of digestion of starch and disaccharides that are abundant in human diet [20]. Inhibitors of $\alpha$-amylase and $\alpha$-glucosidase delay the breakdown of carbohydrate in the small intestine and decrease the postprandial blood glucose excursion levels in diabetic patients. The inhibition of these two prominent enzymes has been found as a useful and effective strategy to lower the levels of postprandial hyperglycemia [21].

Moreover oxidative stress has been implicated in various pathological conditions involving cardiovascular disease, cancer, neurological disorders (Alzheimer's disease and Parkinson's disease), diabetes, ischemia/reperfusion, other diseases and ageing. Convincing evidence for the association of oxidative/nitrosative stress and acute and chronic diseases lies on validated biomarkers of oxidative stress [22]. For this reasons we have also investigated the antioxidant potential of yacon extracts by five different assays. In conclusion, the aim of this study was to investigate the biological properties, including antioxidant, antidiabetic and anticholinesterase activity, and the phytochemical profiles of leaf methanol extracts of fourteen yacon landraces.

\section{Results and Discussion}

\subsection{Extraction Yields, Total Polyphenolic, Tannin and Flavonoid Content}

Dried foliar tissue of 14 landraces of yacon was extracted by maceration technique by solvents of crescent polarity: $n$-hexane (E), chloroform (C), chloroform:methanol 9:1 (CM) and methanol (M). Dried extract yield was calculated. Data showed the different extractive capacities of each solvent. Methanol was the solvent with the highest extractive capacity, the percentage of yield ranged from $4.5 \%$ to $9.8 \%$ followed by $n$-hexane (3.2\% to $6.9 \%$ ); in fact, the latter solvent allows to extract mainly the chlorophylls, abundant in the leaf tissue. The percentage of yield obtained by chloroform and chloroform:methanol mixture (9:1) ranged from $2.3 \%$ to $3.8 \%$ and from $0.7 \%$ to $3.0 \%$, respectively.

The total polyphenolic content (TPC) of different extracts of 14 genotypes of yacon was determined by Folin-Ciocalteu assay. According to literature, methanol extracts show higher content of phenolic compounds than other extracts (data not shown); phenols are also the main responsible compounds of the antioxidant activity; for this reason, the leaf methanol extracts of fourteen yacon landraces have been further analyzed [23]. Results of methanol extracts were expressed as mg of gallic acid equivalent 
(GAE)/g of dried extract (Table 1), by using a standard curve. Yacon landraces displayed quantitative differences in TPC, with a mean value of $74.47 \mathrm{mg} \mathrm{GAE} / \mathrm{g}$. The TPC ranged from $58.49 \pm 1.03$ to $91.07 \pm 4.87 \mathrm{mg} \mathrm{GAE} / \mathrm{g}$ of dried extract, in methanol extracts of PER07 (PER07-M) and PER09-M, respectively. Methanol extract of polyploid sample ECU44 showed a phenolic content similar to that of the mother plant (ECU41).

Table 1. Results of total polyphenol content (TPC), total flavonoid content (TFC), total tannin content (TTC), ferric reducing power (FRAP), 2,2-diphenyl-1-picrylhydrazyl (DPPH) scavenging activity, lipid peroxidation (LOO') inhibition, nitric oxide ( $\left.{ }^{\circ} \mathrm{NO}\right)$ and superoxide radical anion $\left(\mathrm{O}_{2}{ }^{\cdot-}\right)$ scavenging activities of methanol extracts of investigated yacon landraces.

\begin{tabular}{|c|c|c|c|c|c|c|c|c|}
\hline $\begin{array}{c}\text { Yacon } \\
\text { Landraces }\end{array}$ & $\begin{array}{c}\text { TPC } \\
\text { mg GAE/g }\end{array}$ & $\begin{array}{c}\text { TFC } \\
\text { mg QE/g }\end{array}$ & $\begin{array}{c}\text { TTC } \\
\text { mg TAE/g }\end{array}$ & $\begin{array}{c}\text { FRAP } \\
(\mathrm{mg} \mathrm{TE} / \mathrm{g})\end{array}$ & $\begin{array}{l}\text { DPPH } \\
\left(\mathrm{IC}_{50}\right) \\
\end{array}$ & $\begin{array}{l}\mathrm{LOO}^{*} \\
\left(\mathrm{IC}_{50}\right) \\
\end{array}$ & $\begin{array}{c}\mathrm{NO} \\
\left(\mathrm{IC}_{25}\right) \\
\end{array}$ & $\begin{array}{c}\mathrm{O}_{2}^{--} \\
\left(\mathrm{IC}_{50}\right) \\
\end{array}$ \\
\hline PER01-M & $58.64 \pm 1.04$ & $99.59 \pm 1.43$ & $8.52 \pm 0.67$ & $31.55 \pm 0.96$ & $4.21 \pm 0.35$ & $0.51 \pm 0.05$ & $0.27 \pm 0.04$ & $3.81 \pm 0.29$ \\
\hline PER02-M & $84.32 \pm 1.57$ & $104.10 \pm 2.45$ & $8.97 \pm 0.28$ & $45.45 \pm 4.91$ & $3.58 \pm 0.23$ & $0.61 \pm 0.03$ & $0.09 \pm 0.01$ & $2.17 \pm 0.32$ \\
\hline PER03-M & $78.64 \pm 2.63$ & $78.19 \pm 1.59$ & $7.29 \pm 0.08$ & $42.53 \pm 2.42$ & $4.13 \pm 0.50$ & $0.97 \pm 0.08$ & $0.11 \pm 0.01$ & $3.48 \pm 0.25$ \\
\hline PER04-M & $79.43 \pm 1.97$ & $71.93 \pm 1.39$ & $6.38 \pm 0.03$ & $65.32 \pm 6.04$ & $2.08 \pm 0.99$ & $0.91 \pm 0.06$ & $0.08 \pm 0.01$ & $1.85 \pm 0.04$ \\
\hline PER05-M & $85.76 \pm 1.65$ & $98.43 \pm 3.18$ & $12.94 \pm 0.16$ & $45.86 \pm 2.24$ & $3.36 \pm 0.28$ & $0.94 \pm 0.11$ & $0.08 \pm 0.01$ & $3.30 \pm 0.06$ \\
\hline PER06-M & $76.56 \pm 1.48$ & $82.28 \pm 2.22$ & $9.48 \pm 0.37$ & $46.16 \pm 2.83$ & $3.94 \pm 0.45$ & $1.04 \pm 0.10$ & $0.14 \pm 0.01$ & $2.83 \pm 0.20$ \\
\hline PER07-M & $58.49 \pm 0.78$ & $93.00 \pm 1.57$ & $7.20 \pm 0.48$ & $37.25 \pm 4.59$ & $4.39 \pm 0.32$ & $0.67 \pm 0.03$ & $0.09 \pm 0.002$ & $3.40 \pm 0.29$ \\
\hline PER08-M & $60.80 \pm 0.69$ & $58.01 \pm 0.48$ & $6.45 \pm 0.30$ & $39.55 \pm 3.46$ & $4.19 \pm 0.47$ & $1.26 \pm 0.05$ & $0.16 \pm 0.02$ & $3.52 \pm 0.10$ \\
\hline PER09-M & $91.07 \pm 1.41$ & $91.72 \pm 3.46$ & $10.31 \pm 0.80$ & $66.80 \pm 1.90$ & $2.89 \pm 0.12$ & $0.64 \pm 0.04$ & $0.05 \pm 0.006$ & $1.81 \pm 0.08$ \\
\hline PER10-M & $68.43 \pm 3.84$ & $67.59 \pm 1.90$ & $14.58 \pm 0.47$ & $41.68 \pm 4.42$ & $3.37 \pm 0.20$ & $0.95 \pm 0.08$ & $0.08 \pm 0.01$ & $2.11 \pm 0.34$ \\
\hline PER11-M & $85.09 \pm 6.73$ & $74.41 \pm 3.25$ & $14.28 \pm 0.14$ & $53.76 \pm 4.66$ & $3.70 \pm 0.41$ & $0.52 \pm 0.06$ & $0.08 \pm 0.02$ & $2.30 \pm 0.07$ \\
\hline ECU41-M & $72.88 \pm 3.85$ & $62.43 \pm 1.47$ & $9.33 \pm 0.55$ & $45.97 \pm 0.18$ & $3.55 \pm 0.29$ & $1.19 \pm 0.13$ & $0.03 \pm 0.002$ & $1.40 \pm 0.09$ \\
\hline ECU43-M & $66.78 \pm 2.21$ & $57.17 \pm 1.21$ & $7.63 \pm 0.15$ & $34.83 \pm 3.79$ & $3.64 \pm 0.25$ & $1.20 \pm 0.07$ & $0.09 \pm 0.004$ & $1.94 \pm 0.05$ \\
\hline ECU44-M & $75.81 \pm 4.87$ & $102.37 \pm 5.88$ & $8.13 \pm 0.99$ & $49.79 \pm 2.80$ & $3.51 \pm 0.43$ & $0.83 \pm 0.04$ & $0.04 \pm 0.001$ & $0.81 \pm 0.05$ \\
\hline
\end{tabular}

$(\mathrm{GAE}) / \mathrm{g}=\mathrm{mg}$ gallic acid equivalent per gram of dried extract; $(\mathrm{QE}) / \mathrm{g}=\mathrm{mg}$ of quercetin equivalent per gram of dried extract; $(\mathrm{TAE}) / \mathrm{g}=\mathrm{mg}$ of tannic acid equivalent per gram of dried extract; $(\mathrm{TE}) / \mathrm{g}=\mathrm{mg}$ of trolox equivalent per gram of dried extract; $\mathrm{IC}_{50}$ and $\mathrm{IC}_{25}(\mathrm{mg} / \mathrm{mL})=50 \%$ and $25 \%$ inhibitory concentrations, respectively.

Tannins and flavonoids are secondary metabolites that are widely distributed in the plant kingdom and that exhibit various biological properties [24].

Protein precipitation assays represent the operational property to measure the amount of both condensed and hydrolysable tannins. As reported by Hagerman and Butler [25], bovine serum albumin (BSA) was used as protein in this study. Ferric chloride reacts with phenolic compounds in solution to form complexes with the general formula $\mathrm{Fe}-(\mathrm{OR}) 6^{-3}$ where $-\mathrm{OR}^{-}$represents the ionized phenol. The maximum absorption wavelength of the complex is dependent upon the nature of the phenol and the solvent; the complex formed between tannins and ferric chloride in alkaline solution is violet $\left(\lambda_{\max } 510 \mathrm{~nm}\right)$. The triethanolamine, necessary for the maintenance of high $\mathrm{pH}$, was incorporated into the detergent sodium dodecyl suplhate (SDS) solution used to dissolve the tannin-protein complex.

Tannin content was expressed as mg tannic acid equivalent (TAE)/g of dried extract by using a standard curve and results are reported in Table 1. 
PER10-M and PER11-M extracts of yacon showed the highest tannin content, $14.58 \pm 0.47$ and $14.28 \pm 0.14 \mathrm{mg}$ TAE$/ \mathrm{g}$, respectively. In addition, PER05-M (12.94 $\pm 0.16 \mathrm{mg}$ TAE/g) and PER09-M $(10.31 \pm 0.80 \mathrm{mg}$ TAE/g) exhibited a value higher than mean value (9.39 mg TAE/g). The lowest content was observed for PER04-M extract $(6.38 \pm 0.03 \mathrm{mg}$ TAE/g), followed by PER08-M $(6.45 \pm 0.30 \mathrm{mg}$ TAE$/ \mathrm{g})$. The polyploids landraces, ECU43-M (7.63 $\pm 0.15 \mathrm{mg}$ TAE/g) and ECU44-M $(8.13 \pm 0.99 \mathrm{mg} \mathrm{TAE} / \mathrm{g})$, showed lower content than their mother plant, ECU41-M $(9.33 \pm 0.55 \mathrm{mg} \mathrm{TAE} / \mathrm{g})$.

The spectrophotometric assay based on aluminum complex formation is one of the most commonly used procedure for the total flavonoid determination.

Aluminum chloride forms acid stable complexes with the C-4 keto group and either the C-3 or C-5 hydroxyl group of flavones and flavonols. In addition, aluminum chloride forms acid labile complexes with the ortho-dihydroxyl groups in the A or B rings of flavonoids [26].

Total flavonoid content was expressed as $\mathrm{mg}$ of quercetin equivalent (QE)/g of dried extract (Table 1).

ECU44-M and PER02-M showed the highest content of flavonoids, $104.10 \pm 2.45$ and $102.37 \pm 5.88 \mathrm{mg} \mathrm{QE} / \mathrm{g}$, respectively. Flavonoid content, higher than the mean value $(841.52 \mathrm{mg} \mathrm{QE} / \mathrm{g}$ of dried extract) was observed in PER01-M (99.59 $\pm 1.43 \mathrm{mg} \mathrm{QE} / \mathrm{g})$, PER05-M (98.43 $\pm 3.18 \mathrm{mg}$ QE/g), PER07-M (93.00 $\pm 1.57 \mathrm{mg} \mathrm{QE} / \mathrm{g})$ and PER09-M (91.72 $\pm 3.46 \mathrm{mg} \mathrm{QE} / \mathrm{g})$. The lowest content was observed in the polyploid sample ECU43-M $(57.17 \pm 1.21 \mathrm{mg} \mathrm{QE} / \mathrm{g})$, more similar to its mother plant ECU41-M (62.43 $\pm 1.47 \mathrm{mg} \mathrm{QE} / \mathrm{g})$ and PER08-M (58.01 $\pm 0.48 \mathrm{mg} \mathrm{QE} / \mathrm{g})$.

In-vitro assays used in this study are most often colorimetric methods of choice for general determinations of polyphenols, tannins and flavonoids. Although the presence of other constituents in the crude extract could slightly interfere with their quantification, these methods are routinely used [27,28].

\subsection{In-Vitro Biological Activity}

\subsubsection{Reducing Power by Ferric Reducing Antioxidant Power (FRAP) Test}

Generally, phenolic compounds are responsible for biological activities as antioxidant capacity and inhibition of enzymes involved in common diseases. Antioxidant activity should not be based on a single antioxidant test model and in practice several in vitro test procedures are carried out for evaluating antioxidant activities with the samples of interest [29]. The ferric reducing antioxidant power (FRAP) method is based on the reduction of the $\mathrm{Fe}^{3+}$ complex of tripyridyltriazine $\left(\mathrm{Fe}(\mathrm{TPTZ})^{3+}\right.$ ) to the intensely blue colored $\mathrm{Fe}^{2+}$ complex $\left(\mathrm{Fe}(\mathrm{TPTZ})^{2+}\right.$ ) by antioxidants. The method is simple and rapid; it was originally applied to plasma but has been extended to other biological fluids, foods, plant extracts, juices, etc.

Results (Table 1) ranged from $31.55 \pm 0.96$ to $66.80 \pm 1.90 \mathrm{mg}$ of Trolox Equivalent (TE)/g of dried extract. Extracts of PER09-M and PER04-M landraces showed the highest reducing power, $66.80 \pm 1.90$ and $65.32 \pm 6.04 \mathrm{mg}$ TE/g of dried extract, respectively. Sample PER01-M $(31.55 \pm 0.96 \mathrm{mg} \mathrm{TE} / \mathrm{g})$ exhibited the lowest value, followed by PER07-M (37.25 $\pm 4.59 \mathrm{mg}$ TE/g), PER08-M (39.55 $\pm 3.46 \mathrm{mg}$ $\mathrm{TE} / \mathrm{g})$ and ECU43-M (34.83 $\pm 3.79 \mathrm{mg} \mathrm{TE} / \mathrm{g})$. ECU44-M (49.79 $\pm 2.80 \mathrm{mg} \mathrm{TE} / \mathrm{g})$ showed higher reducing power than ECU41-M (45.97 $\pm 0.15 \mathrm{mg} \mathrm{TE} / \mathrm{g})$, its mother plant. 


\subsubsection{Radical Scavenging Activity by 2,2-Diphenyl-1-picrylhydrazyl (DPPH) Assay}

In vitro antioxidant tests using free radical traps are relatively straightforward to perform. Among free radical scavenging methods, the one involving 2,2-diphenyl-1-picrylhydrazyl (DPPH) is rapid, simple, highly reproducible and inexpensive in comparison to other test models. The scavenging of the stable DPPH radical is widely used to evaluate the antioxidant activity of phenolic compounds extracted from fruits, vegetables, cereal grains, wine, etc. [30]. The method is based on the reduction of methanol DPPH solution in the presence of a hydrogen donating antioxidant, due to the formation of the non-radical form DPPH-H. The extracts were able to reduce the stable radical DPPH to the yellow colored diphenylpicrylhydrazine, in a concentration-dependent manner. Results were expressed as IC50 (Table 1) and all extracts showed a fair DPPH scavenging activity, lower than Trolox (used as standard) with an IC50 of $0.08 \pm 0.002 \mathrm{mg} / \mathrm{mL}$. The most active of the yacon landraces was PER04-M $\left(\mathrm{IC}_{50}=2.08 \pm 0.99 \mathrm{mg} / \mathrm{mL}\right)$ followed by PER09-M ( $\left.\mathrm{IC}_{50}=2.89 \pm 0.12 \mathrm{mg} / \mathrm{mL}\right)$. PER01-M ( $\left.\mathrm{IC}_{50}=4.21 \pm 0.35 \mathrm{mg} / \mathrm{mL}\right)$, PER08-M $\left(\mathrm{IC}_{50}=4.19 \pm 0.47 \mathrm{mg} / \mathrm{mL}\right)$ and PER07-M $\left(\mathrm{IC}_{50}=4.39 \pm 0.32 \mathrm{mg} / \mathrm{mL}\right)$ showed the lowest activity. Methanol extract of polyploids samples (ECU43-M and ECU44-M) and their mother plant (ECU41-M) displayed similar DPPH-scavenging activity.

\subsubsection{Nitric Oxide ( NO) Radical Scavenging Activity}

'NO is known to be a ubiquitous free radical, being distributed in tissues or organ systems and supposed to have a vital role in neuromodulation or as a neurotransmitter in the central nervous system CNS. In addition to reactive oxygen species, nitric oxide is also implicated in inflammation, cancer and other pathological conditions. In the in vitro assay performed, sodium nitroprusside is known to decompose in aqueous solution at physiological $\mathrm{pH}$ (7.2) producing NO [31]. Under aerobic conditions, NO reacts with oxygen to produce stable products (nitrate and nitrite), the quantities of which can be determined using Griess reagent [32]. The Griess reaction is based on the two-step diazotization reaction in which acidified $\mathrm{NO}_{2}^{-}$produces a nitrosating agent, which reacts with sulfanilic acid to produce the diazonium ion. This ion is then coupled to $N$-(1-naphthyl) ethylenediamine to form a chromophoric azo-derivative, absorbing at $560 \mathrm{~nm}$ [33].

The ability to inhibit nitric oxide production was concentration-dependent and, as far as we know, not reported yet for yacon leaf extract. The $\mathrm{IC}_{50}$ was not reached with the tested concentrations, so the results were expressed as $\mathrm{IC}_{25}(\mathrm{mg} / \mathrm{mL})$ and are reported in Table 1. Ascorbic acid was used as reference, showing a $\mathrm{IC}_{25}$ value of $0.06 \pm 0.003 \mathrm{mg} / \mathrm{mL}$. All extracts demonstrated to possess nitric oxide scavenging activity. Foliar extracts of ECU41-M $\left(\mathrm{IC}_{25}=0.03 \pm 0.002 \mathrm{mg} / \mathrm{mL}\right)$ and ECU44-M $\left(\mathrm{IC}_{25}=0.04 \pm 0.001 \mathrm{mg} / \mathrm{mL}\right)$ showed the highest scavenging activity; also PER09-M $\left(\mathrm{IC}_{25}=0.05 \pm 0.006 \mathrm{mg} / \mathrm{mL}\right)$ reported a good scavenging activity, higher than ascorbic acid. Sample PER01-M, with the highest $\mathrm{IC}_{25}$ value $(0.27 \pm 0.04 \mathrm{mg} / \mathrm{mL})$, was the less active.

\subsubsection{Superoxide Radical $\left(\mathrm{O}_{2}{ }^{--}\right)$Scavenging Activity}

The production of reactive oxygen species, such as superoxide $\left(\mathrm{O}_{2}{ }^{\cdot-}\right)$, by mitochondria is a major cause of cellular oxidative stress and it contributes to many pathological conditions [34]. Superoxide anion radical $\left(\mathrm{O}_{2}{ }^{\cdot-}\right)$ is generated in aerobic cells due to electron leakage from the electron transport chain. 
In this study, in vitro superoxide anions are generated by phenazine methosulfate- $\beta$-nicotinamide adenine dinucleotide (PMS-NADH) system. The superoxide scavenging capacity of methanol extracts was quantified by their ability to inhibit nitrotetrazolium blue chloride (NBT) reduction by superoxide.

Scavenging activity was, also in this case, concentration-dependent and the activity of ascorbic acid, used as reference, was compared with the samples by $\mathrm{IC}_{50}$ values. Ascorbic acid displayed the strongest activity, showing the lowest $\mathrm{IC}_{50}(0.28 \pm 0.04 \mathrm{mg} / \mathrm{mL})$. Methanol extract of ECU44-M exhibited the lowest $\mathrm{IC}_{50}$ value among investigated landraces ( $\mathrm{IC}_{50}=0.81 \pm 0.05 \mathrm{mg} / \mathrm{mL}$ ), so it was the most active against superoxide radical obtaining a comparable value to ascorbic acid, used as positive control. Also PER09-M ( $\left.\mathrm{IC}_{50}=1.81 \pm 0.08 \mathrm{mg} / \mathrm{mL}\right)$, PER04-M $\left(\mathrm{IC}_{50}=1.85 \pm 0.04 \mathrm{mg} / \mathrm{mL}\right)$ and PER02-M $\left(\mathrm{IC}_{50}=2.17 \pm 0.32 \mathrm{mg} / \mathrm{mL}\right)$ showed a good superoxide anion scavenging activity, with an $\mathrm{IC}_{50}$ lower than mean value $\left(\mathrm{IC}_{50}=2.48 \mathrm{mg} / \mathrm{mL}\right.$ ). PER01-M was the weakest physiological radicals scavenger, both against superoxide radical $\left(\mathrm{IC}_{50}=3.81 \pm 0.29 \mathrm{mg} / \mathrm{mL}\right)$ and ${ }^{\circ} \mathrm{NO}$.

\subsubsection{Lipid Peroxidation (LOO`) Inhibition Test}

Lipid peroxidation is thought to be an important factor in the pathophysiology of a number of diseases. Lipid peroxidation is probably the most extensively investigated free radical-induced process [35]. In this study, lipid peroxidation inhibition was assessed by evaluating the formation of conjugated dienes, structures with a double-single-double bond $(-\mathrm{C}=\mathrm{C}-\mathrm{C}=\mathrm{C}-$ ) arrangement, absorbing $\mathrm{UV}$ light in the wavelength range 230-235 nm [36-38].

This test was used in the antioxidant activity evaluation of the methanol extracts of yacon. Results were expressed as $\mathrm{IC}_{50}$ (Table 1). Butylated hydroxytoluene (BHT) was used as reference, showing the highest inhibition of lipid peroxidation $\left(\mathrm{IC}_{50}=0.01 \pm 0.001 \mathrm{mg} / \mathrm{mL}\right.$ ). All extracts displayed $\mathrm{IC}_{50}$ values higher than the reference compound. Among all extracts, the most able to scavenge LOO were PER01-M $\left(\mathrm{IC}_{50}=0.51 \pm 0.05 \mathrm{mg} / \mathrm{mL}\right)$ and PER11-M $\left(\mathrm{IC}_{50}=0.52 \pm 0.06 \mathrm{mg} / \mathrm{mL}\right) ;$ similar values were also observed with PER02-M $\left(\mathrm{IC}_{50}=0.61 \pm 0.03 \mathrm{mg} / \mathrm{mL}\right)$, PER09-M $\left(\mathrm{IC}_{50}=0.64 \pm 0.04 \mathrm{mg} / \mathrm{mL}\right)$ and PER07-M $\left(\mathrm{IC}_{50}=0.67 \pm 0.03 \mathrm{mg} / \mathrm{mL}\right)$, whereas the lowest capacity was found for PER08-M $\left(\mathrm{IC}_{50}=1.26 \pm\right.$ $0.05 \mathrm{mg} / \mathrm{mL})$, ECU43-M (IC50 $=1.20 \pm 0.07 \mathrm{mg} / \mathrm{mL})$ and ECU41-M $\left(\mathrm{IC}_{50}=1.19 \pm 0.13 \mathrm{mg} / \mathrm{mL}\right)$.

\subsubsection{Inhibition Activity against $\alpha$-Glucosidase and $\alpha$-Amylase Enzymes}

Medicinal plants and herbal extracts containing glycosides, flavonoids, tannins, etc., have been reported to demonstrate antidiabetic [39] and anticholinesterase activities [40]. One therapeutic approach for treating diabetes is to decrease post-prandial hyperglycemia. This is done by hindering the absorption of glucose through inhibition of the carbohydrate hydrolyzing enzymes, $\alpha$-amylase and $\alpha$-glucosidase, in the digestive tract. In our investigation, the inhibitory activity of crude methanol extracts against both mentioned enzymes was carried out. Previous study reported only the $\alpha$-glucosidase inhibitory activity of some isolated constituents from yacon leaves [6].

Results were expressed as $\mathrm{IC}_{50}$. Acarbose was used as reference drug showing IC $_{50}$ values lower than $0.20 \mathrm{mg} / \mathrm{mL}$ in both inhibition assays. Data obtained showed that methanol extracts of yacon leaves were stronger inhibitors of $\alpha$-amylase than $\alpha$-glucosidase, as presented in Figure 1a. Among yacon extracts, the most active was found to be ECU44-M landrace for both enzyme inhibitory activities ( $\mathrm{IC}_{50}=0.26 \pm 0.02 \mathrm{mg} / \mathrm{mL}$ for $\alpha$-amylase inhibition and $1.30 \pm 0.04 \mathrm{mg} / \mathrm{mL}$ for $\alpha$-glucosidase); 
ECU41-M and PER09-M extracts act as $\alpha$-amylase inhibitors; additionally, PER11-M can be considered a moderate inhibitor of $\alpha$-glucosidase; on the other hand, the less active against both enzymes were PER01-M and PER04-M extracts.

According to previous study [6], our investigation reported that methanol extracts moderately inhibited $\alpha$-amylase and $\alpha$-glucosidase and this result can, at least partially, explain the traditional use of yacon leaves for treating hyperglycemia.

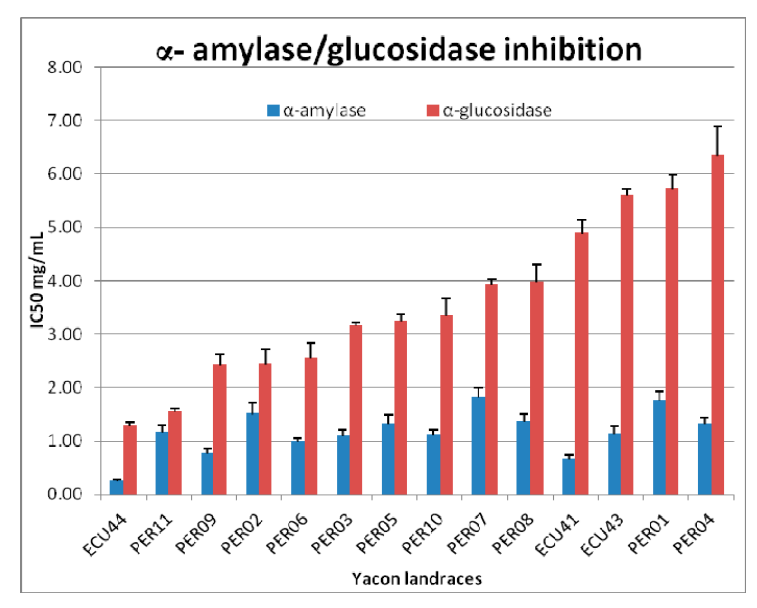

(a)

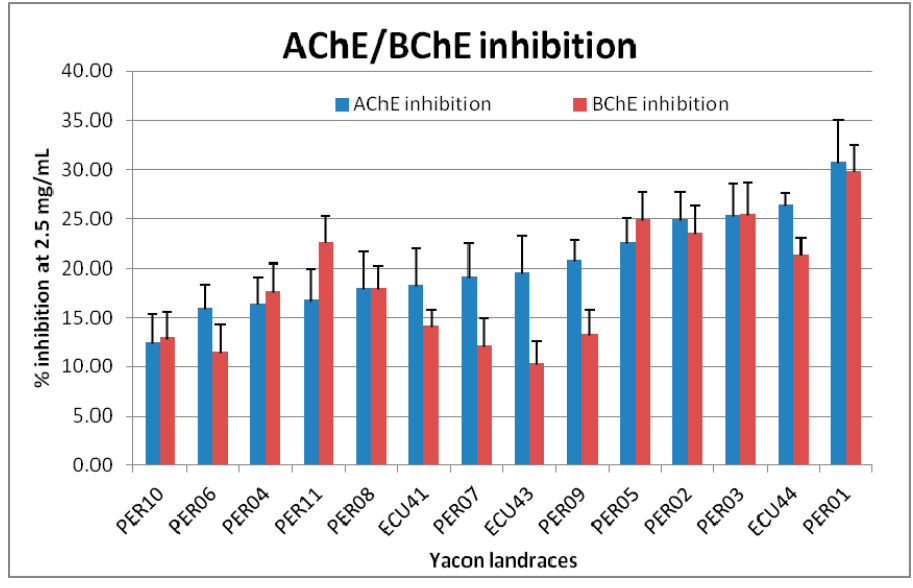

(b)

Figure 1. (a) $\alpha$-Amylase and $\alpha$-glucosidase inhibition activity and (b) acetylcholinesterase $(\mathrm{AChE})$ and butyrylcholinesterase (BChE) inhibition of tested yacon extracts.

\subsubsection{Inhibition Activity against Acetylcholinesterase and Butyrylcholinesterase Enzymes}

For the first time yacon extracts were tested to evaluate their capacity to inhibit the cholinesterase enzymes. The crucial role of the cholinesterases in neural transmission makes them a primary target of a large number of cholinesterase-inhibiting drugs and this has relevance to the treatment of neurodegenerative disorders.

The method for the screening of ChE inhibitory activity from natural resources based on Ellman's reactions has been reported [41]. In 1959, Ellman introduced 5,5'-dithio-bis-(2-nitrobenzoic acid), also known as DTNB, as a versatile water-soluble compound for quantitating free sulfhydryl groups in solution. A solution of this compound produces a measurable yellow-colored product when it reacts with sulfhydryl. Consequently, Ellman's reagent is very useful as a sulfhydryl assay reagent because of its specificity for $-\mathrm{SH}$ groups at neutral $\mathrm{pH}$, high molar extinction coefficient and short reaction time. DTNB reacts with a free sulfhydryl group to yield a mixed disulfide and 2-nitro-5-thiobenzoic acid (TNB). The target of DTNB in this reaction is the conjugated base ( $\mathrm{R}-\mathrm{S}-$ ) of a free sulfhydryl group.

In the in vitro assays, AChE and BChE efficiently catalyze the hydrolysis of acetyl- and butyryl-thiocholine (AcSCh and $\mathrm{BuSCh}$ ), sulfur analogs of their respective natural substrate, acetylcholine. Upon hydrolysis, these substrate analogs produce acetate (or butyrate) and thiocholine. Thiocholine in the presence of the highly reactive DTNB ion reacts to generate the yellow 5-thio-2-nitrobenzoate anion. The yellow color can be quantified at $405 \mathrm{~nm}$ [41]. 
Galantamine, a natural cholinesterase inhibitor used in therapeutics, was used as reference and its capacity to inhibit the two enzymes involved in Alzheimer' disease was measured: $93.5 \% \pm 1.2 \%$ AChE inhibition and $68.3 \% \pm 3.4 \%$ BChE inhibition, at only $0.01 \mathrm{mg} / \mathrm{mL}$.

Yacon landraces demonstrated a concentration-dependent inhibition, but unfortunately the weak activity of the extracts did not allow to reach, and consequently calculate, the IC50. In fact, results were expressed as \% of inhibition at $2.5 \mathrm{mg} / \mathrm{mL}$, and they showed an inhibition lower than $35 \%$ against both enzymes.

Among them, PER01-M showed the strongest capacity against both $\mathrm{AChE}$ and $\mathrm{BChE}$, in this case similar values have been found: $30.87 \% \pm 4.20 \%$ and $29.83 \% \pm 2.68 \%$, respectively. Most of the yacon landraces displayed the same effect against both cholinesterases, showing an inhibition lower than $25 \%$ at the tested concentration.

\subsection{High Perfomance Liquid Chromatography-Diode Array Detector Analysis}

Phenolic compounds have characteristic UV-Vis spectral properties that are unique for each of the different classes of phenolics, and may therefore be used for tentative identification of the class of a phenolic compound.

Phytochemical studies of yacon leaves showed the presence of several melampolide-type sesquiterpene lactones such as sonchifolin, uvedalin, enhydrin, fluctuanin [42] and phenolic compounds, mainly chlorogenic acid and other caffeic derivatives, have been identified in different extracts of yacon leaves together with some flavonoids [7,12,43-45].

High perfomance liquid chromatography-diode array detector (HPLC-DAD) analysis of methanol extract of yacon leaves confirmed the presence of rutin and caffeic acid. Other compounds were identified by comparing with the results obtained with Cynara cardunculus extract analyzed under the same conditions [46]. Methanol extract of $C$. cardunculus is characterized to be rich in caffeoylquinic acids and analytical parameters allowed to identify chlorogenic acid, 3,5-O-dicaffeoylquinic acid, 1,5-O-dicaffeoylquinic acid and 4,5-O-di-caffeoylquinic acid. The compound 1,5-O-dicaffeoylquinic acid was identified for the first time in yacon leaves.

Analyzing HPLC chromatograms, it is possible to observe a similar phytochemical profile; it was just reported a representative chromatogram (Figure 2). Quantitative analysis demonstrated that all samples contained a high amount of phenolic acids. Results are reported in Table 2.

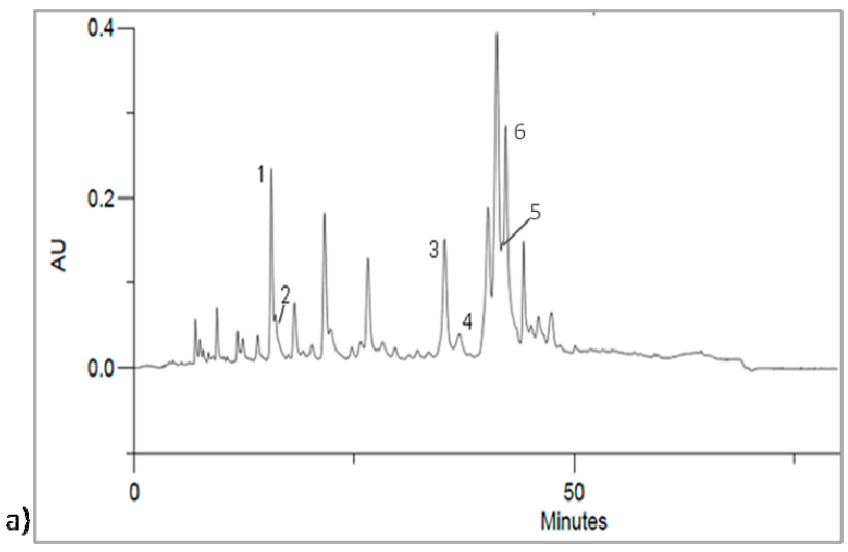

Figure 2. Cont. 
b)
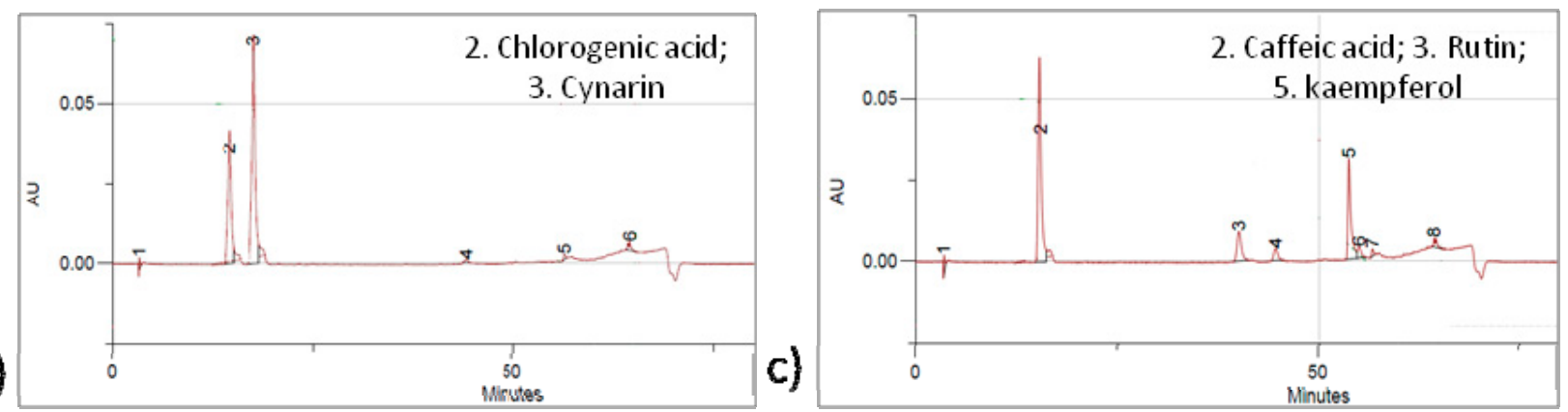

Figure 2. (a) Chromatogram obtained by high perfomance liquid chromatography-diode array detector $(320 \mathrm{~nm})$ of methanol extract of PER02 landrace. 1: Chlorogenic acid $(\mathrm{Rt}=14.95 \mathrm{~min}), 2:$ Caffeic acid $(\mathrm{Rt}=15.18 \mathrm{~min}), 3: 3,5$-di- $O$-caffeoylquinic acid $(\mathrm{Rt}=33.86 \mathrm{~min}), 4:$ 1,5-di- $O$-caffeoylquinic acid $(\mathrm{Rt}=35.60 \mathrm{~min}), \mathbf{5}:$ Rutin $(\mathrm{Rt}=39.68 \mathrm{~min})$, 6: 4,5-di-O-caffeoylquinic acid $(\mathrm{Rt}=41.29 \mathrm{~min})$; (b) HPLC chromatogram $(320 \mathrm{~nm})$ of the standards: chlorogenic acid $(\mathrm{Rt}=14.72 \mathrm{~min})$ and cynarin $(\mathrm{Rt}=17.62 \mathrm{~min})$; $(\mathbf{c})$ HPLC chromatogram $(320 \mathrm{~nm})$ of the standards caffeic acid $(\mathrm{Rt}=15.31 \mathrm{~min})$, rutin $(\mathrm{Rt}=39.59 \mathrm{~min})$ and kaempferol $(\mathrm{Rt}=53.38 \mathrm{~min})$.

Chlorogenic acid is the most abundant compound and it was already found both in leaves and root of yacon $[42,47]$. It ranged from 13,033.96 $\pm 121.60 \mathrm{mg}$ of chlorogenic acid/kg of extract (PER09-M) to $1383.44 \pm 2.16 \mathrm{mg}$ of chlorogenic acid/ $\mathrm{kg}$ of extract (PER01-M). High content of this compound was found in PER11-M (10,069.14 $\pm 64.17 \mathrm{mg}$ of chlorogenic acid/kg of extract) and PER10-M $(9930.52 \pm 58.32$ of chlorogenic acid/kg of extract). Among identified caffeoylquinic acids, high content of 3,5- and 4,5-O-dicaffeoylquinic acids was also observed, with mean values of 4018.70 and $2424.57 \mathrm{mg}$ cynarin/kg, while 1,5-O-dicaffeoylquinic acid was found in small amounts in the extracts (Table 2).

Among all methanol extracts, PER09-M contained the highest amount of secondary metabolites, both flavonoids and phenolic acids, and in particular, it was found to be rich in caffeic and chlorogenic acids. The ECU44 landraces showed large amounts of phenylpropanoid derivatives and, among all identified compounds, caffeoylquinic acids are abundant. Sample ECU41-M, together with its polyploids, ECU43-M and ECU44-M, demonstrated the highest content of 3,5-O-dicaffeoylquinic acid. PER01-M was the sample with the lowest content of secondary metabolites, in particular it showed a low content of phenylpropanoid acids, but together with PER02-M, contained a high amount of rutin and flavonoid derivatives. PER08-M showed the lowest content of rutin and flavonoids, according to the results obtained by colorimetric assay. 
Table 2. HPLC quantification of identified compounds in yacon landraces.

\begin{tabular}{|c|c|c|c|c|c|c|}
\hline $\begin{array}{c}\text { Yacon } \\
\text { Landraces }\end{array}$ & $\begin{array}{c}\text { Chlorogenic Acid } \\
\text { (mg Chlorogenic } \\
\text { Acid } / \mathbf{k g} \text { ) }\end{array}$ & $\begin{array}{c}\text { Caffeic Acid } \\
\text { (mg Caffeic } \\
\text { Acid/kg) }\end{array}$ & $\begin{array}{c}\text { 3,5-O-di- } \\
\text { Caffeoylquinic } \\
\text { Acid } \\
(\mathrm{mg} \text { Cynarin } / \mathrm{kg} \text { ) }\end{array}$ & $\begin{array}{c}\text { 1,5- } O \text {-di- } \\
\text { Caffeoylquinic } \\
\text { Acid } \\
(\mathrm{mg} \text { Cynarin } / \mathrm{kg})\end{array}$ & $\begin{array}{c}\text { 4,5-O-di- } \\
\text { Caffeoylquinic } \\
\text { Acid } \\
(\mathrm{mg} \text { Cynarin } / \mathrm{kg})\end{array}$ & $\begin{array}{c}\text { Rutin } \\
\text { (mg Rutin/kg) }\end{array}$ \\
\hline PER01-M & $1383.44 \pm 2.16$ & $319.73 \pm 2.90$ & $606.47 \pm 5.97$ & $222.24 \pm 5.28$ & $937.93 \pm 2.84$ & $951.06 \pm 3.51$ \\
\hline PER02-M & $3010.99 \pm 65.66$ & $452.39 \pm 5.05$ & $1741.36 \pm 42.92$ & $442.99 \pm 1.02$ & $1965.34 \pm 31.88$ & $1193.60 \pm 36.31$ \\
\hline PER03-M & $3180.23 \pm 23.86$ & $476.02 \pm 8.78$ & $2555.21 \pm 35.03$ & $303.06 \pm 11.86$ & $1766.98 \pm 169.29$ & $608.75 \pm 8.57$ \\
\hline PER04-M & $5580.74 \pm 26.86$ & $635.86 \pm 16.06$ & $4069.10 \pm 58.98$ & $673.27 \pm 23.67$ & $2857.90 \pm 139.97$ & $548.03 \pm 10.98$ \\
\hline PER05-M & $5004.72 \pm 18.31$ & $697.12 \pm 14.54$ & $3345.68 \pm 36.06$ & $425.54 \pm 25.32$ & $1915.80 \pm 28.12$ & $668.23 \pm 5.81$ \\
\hline PER06-M & $3727.59 \pm 35.54$ & $802.68 \pm 24.60$ & $2587.01 \pm 24.11$ & $597.77 \pm 10.78$ & $1807.18 \pm 22.20$ & $476.23 \pm 5.73$ \\
\hline PER07-M & $5965.41 \pm 45.99$ & $622.39 \pm 28.61$ & $1166.08 \pm 31.01$ & $448.72 \pm 24.00$ & $2868.39 \pm 33.65$ & $657.37 \pm 13.51$ \\
\hline PER08-M & $6799.45 \pm 128.33$ & $732.93 \pm 21.12$ & $3061.57 \pm 46.59$ & $623.67 \pm 66.17$ & $1984.75 \pm 35.12$ & $387.17 \pm 24.63$ \\
\hline PER09-M & $13,033.96 \pm 121.60$ & $1133.52 \pm 36.37$ & $6339.79 \pm 49.55$ & $663.85 \pm 80.83$ & $3998.25 \pm 37.18$ & $803.94 \pm 57.00$ \\
\hline PER10-M & $9930.52 \pm 58.32$ & $1060.62 \pm 28.83$ & $4892.73 \pm 24.78$ & $437.50 \pm 28.59$ & $1880.87 \pm 28.27$ & $958.23 \pm 48.19$ \\
\hline PER11-M & $10,069.14 \pm 64.17$ & $920.17 \pm 14.16$ & $4792.38 \pm 58.39$ & $534.08 \pm 63.73$ & $2671.80 \pm 42.16$ & $870.33 \pm 21.55$ \\
\hline ECU41-M & $8012.71 \pm 52.60$ & $665.86 \pm 16.21$ & $5479.88 \pm 61.82$ & $255.33 \pm 27.66$ & $2378.10 \pm 22.26$ & $1347.27 \pm 50.41$ \\
\hline ECU43-M & $8523.77 \pm 61.15$ & $863.10 \pm 21.50$ & $5934.75 \pm 61.58$ & $367.16 \pm 36.69$ & $3094.95 \pm 34.10$ & $974.84 \pm 28.70$ \\
\hline ECU44-M & $8009.38 \pm 48.36$ & $1047.42 \pm 34.25$ & $9689.76 \pm 101.26$ & $677.11 \pm 10.01$ & $5218.88 \pm 47.30$ & $992.15 \pm 63.60$ \\
\hline
\end{tabular}




\subsection{Statistical Analysis}

To compare data obtained by different chemical method used to evaluate extract antioxidant activity, a new concept, relative antioxidant capacity index (RACI) [48], was proposed. This concept provides a more comprehensive comparison when several samples are analyzed.

All methods used for antioxidant activity determination together with TPC were included in RACI calculation. Recently, TPC assay has been proposed for the measurement of total reducing capacity of samples [49].

Results of antioxidant activity expressed as $\mathrm{IC}_{25}$ or $\mathrm{IC}_{50}$ were converted in $1 / \mathrm{IC}_{25}$ and 1/IC 50 , before the RACI calculation. Data of relative antioxidant activity were represented as histograms (Figure 3). According to obtained results, methanol extract of PER09 sample showed the highest index, 0.87, followed by PER04-M (0.81). Positive value was displayed by ECU44-M (0.67), PER10 (0.39), ECU41 (0.30), PER11 (0.24) and PER02 (0.11). The yacon landrace extract showing the lowest RACI was PER08-M (-0.86). The extracts with the highest RACI contribute in significant manner to the complex antioxidant activity, although they had a different attitude depending on the various used methods.

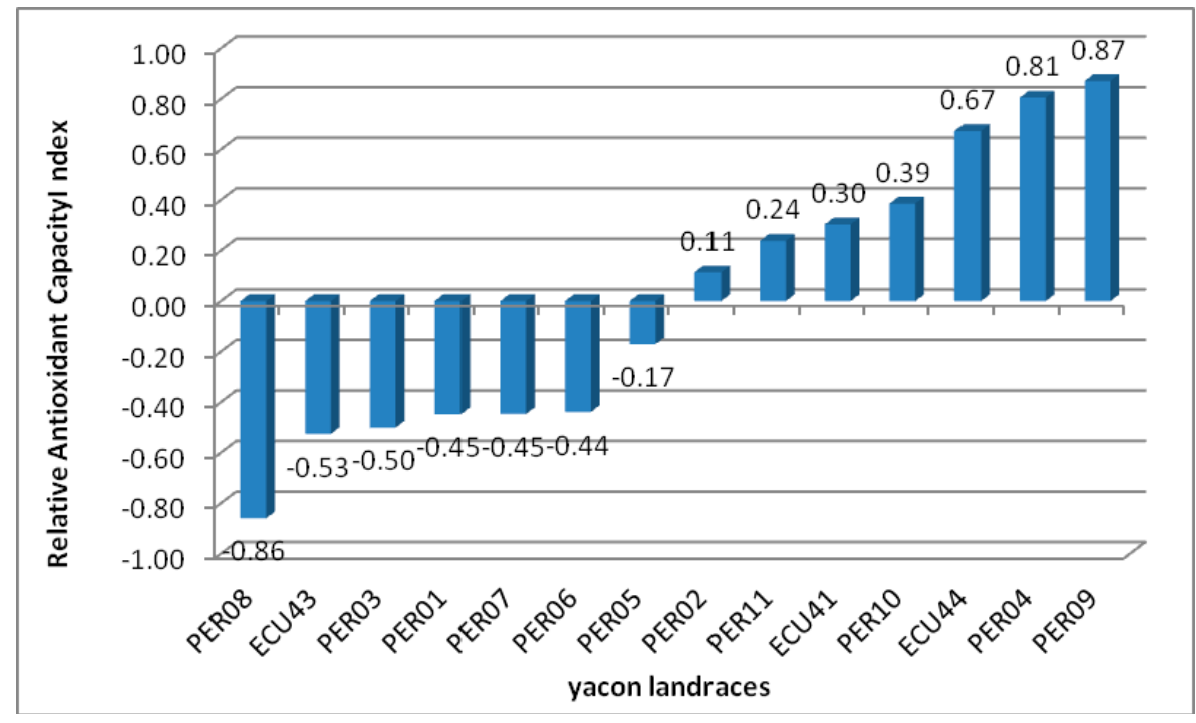

Figure 3. Relative antioxidant capacity index of investigated yacon landraces.

To understand the correlation among all studied variables, total polyphenols, flavonoid and tannin content and biological activity (reducing power, radical-scavenging activity, lipid peroxidation, inhibition of AChE, BChE, $\alpha$-glucosidase and $\alpha$-amylase), Pearson's correlation coefficient was calculated. The analysis was conducted using averaged values of each variable and results are reported in Table 3. Data expressed as $\mathrm{IC}_{50}$ and $\mathrm{IC}_{25}$, show a negative correlation. The highest correlation was observed between total polyphenol content and reducing power $(\mathrm{r}=0.77)$. Polyphenols seem to be mostly involved in scavenging activity against DPPH $(\mathrm{r}=-0.58)$, superoxide radical $(\mathrm{r}=-0.39)$ and nitric oxide $(r=-0.53)$ demonstrating the ability of these compounds to quench radicals and reduce the oxidative and nitrosative stress. Flavonoids were the main contributors to lipid peroxidation inhibition $(\mathrm{r}=-0.72)$. Pearson correlation between phenolic content and enzymatic inhibition was also calculated. Polyphenols showed to be moderately related to $\alpha$-glucosidase $(r=-0.51)$ and $\alpha$-amylase $(r=-0.41)$ enzyme inhibitions, as well flavonoids can contribute to AChE and BChE inhibition 
$(\mathrm{r}=0.66$ and $\mathrm{r}=0.51$, respectively), as previously reported [50]. Among all investigated activities, tannin content demonstrated the highest correlation with $\alpha$-glucosidase inhibition $(r=-0.45)$.

Table 3. Pearson correlation among total polyphenol content (TPC), total tannin content (TTC), total flavonoid content (TFC) and antioxidant activity (reducing power, 2,2-diphenyl-1-picryl hydrazyl (DPPH), $\mathrm{NO}, \mathrm{O}_{2}{ }^{-{ }^{-}}$scavenging activity and lipid peroxidation inhibition) and enzymatic inhibition (AChE, BChE, $\alpha$-amylase and $\alpha$-glucosidase enzymes).

\begin{tabular}{cccc}
\hline Variables & TPC & TTC & TFC \\
\hline Reducing power (FRAP) & 0.77 & 0.14 & 0.08 \\
DPPH scavenging activity & -0.58 & -0.12 & 0.06 \\
Lipid peroxidation inhibition (LOO') & -0.24 & -0.27 & -0.72 \\
NO scavenging activity & -0.53 & -0.23 & 0.11 \\
$\mathrm{O}_{2}{ }^{--}$scavenging activity & -0.39 & -0.11 & 0.09 \\
AChE inhibition & -0.02 & -0.32 & 0.66 \\
BChE inhibition & 0.15 & 0.05 & 0.51 \\
$\alpha$-Amylase inhibition & -0.41 & -0.13 & 0.12 \\
$\alpha$-Glucosidase inhibition & -0.51 & -0.45 & -0.41 \\
\hline
\end{tabular}

In order to discriminate the yacon landraces on the basis of the chemical profile and biological activity, data were normalized and principal component analysis (PCA) was conducted on the correlation matrix. In this study, PCA was used for a better visualization of data sets obtained from the determinations of all studied variables as previously reported [51,52]: content of total phenols, flavonoids, tannin, chlorogenic acid (CHA), caffeic acid (CA), rutin, 1,5-O-di-caffeoylquinic acid (1,5-CQA), 4,5-O-di-caffeoylquinic acid (4,5-CQA), 3,5-O-di-caffeoylquinic acid (3,5-CQA), as well as biological activity (reducing power, radical-scavenging activity, lipid peroxidation, inhibition of AChE, BChE, $\alpha$-glucosidase and $\alpha$-amylase). The use of this unsupervised classification method often permits a simple representation of yacon landraces data and their correlations. The first two principal components (PCs) described 55.93\% of the initial data variability (PC1 36.95\% and PC2 18.99\%) (Figure 4). Further components explained $13.24 \%, 10.08 \%$ and $7.43 \%$ of variance. The loading of PC1 had a strong positive correlation with nitric oxide and superoxide ( $\mathrm{SO}$ ) scavenging activity, $\alpha$-amylase and $\alpha$-glucosidase inhibitions and with the content of CHA, CA, 3,5-CQA and 4,5-CQA. The strong positive loadings of PC2 were total flavonoid content and inhibition of cholinesterase enzymes. Compounds 4,5-CQA and 3,5-CQA showed good correlation with nitric oxide and superoxide scavenging activity and $\alpha$-amylase and $\alpha$-glucosidase inhibition. These compounds were found in high amount in ECU44-M and results were confirmed by PCA analysis. As reported by PCA analysis, flavonoid content, abundant in ECU44-M, PER01-M and PER02-M, are involved in the inhibition of cholinesterase enzymes. 


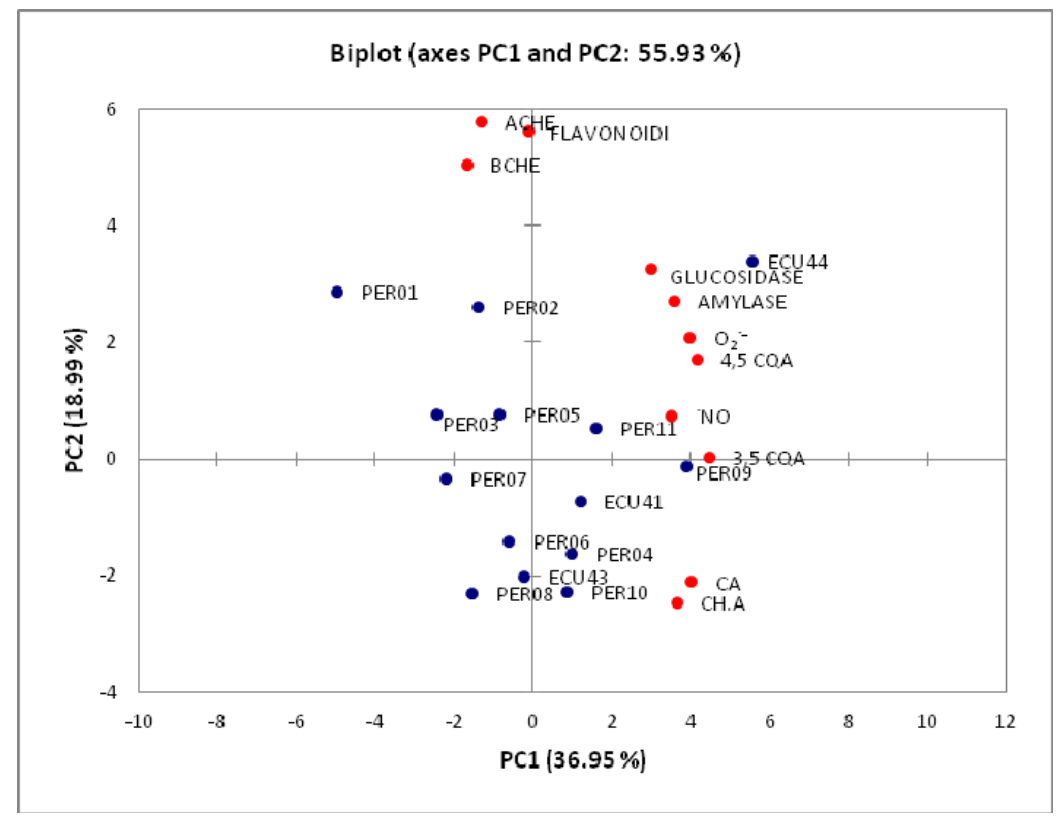

Figure 4. Principal component analysis (PCA) among biological activity and chemical profile of investigated yacon landraces.

\section{Experimental Section}

\subsection{Chemicals}

Chloroform, $n$-hexane, methanol, hydrochloric acid and glacial acetic acid were purchased from Carlo Erba (Milano, Italy). Ethanol, potassium di-hydrogen phosphate, di-sodium tetraborate, iron (II) sulfate $\left(\mathrm{FeSO}_{4} \cdot 7 \mathrm{H}_{2} \mathrm{O}\right)$ and $\mathrm{N}$-(1-naphthyl) ethylenediamine dihydrochloride were obtained from Merck (Darmstadt, Germany). Folin-Ciocalteu reagent 2N, sodium carbonate, sodium acetate trihydrate, 2,4,6-tripyridyl-s-triazine (TPTZ), iron (III) chloride $\left(\mathrm{FeCl}_{3} \cdot 6 \mathrm{H}_{2} \mathrm{O}\right), 2$,2-diphenyl-1-picryl hydrazyl (DPPH) radical, and standards as 6-hydroxy-2,5,7,8-tetramethylchroman-2-carboxylic acid (Trolox) and gallic acid were purchased from Sigma-Aldrich (Milan, Italy). Butylated hydroxytoluene (BHT, 2,6-bis(1,1-dimethylethyl)-4-methylphenol), $\beta$-nicotinamide adenine dinucleotide reduced form (NADH), phenazine methosulfate (PMS), nitrotetrazolium blue chloride (NBT), 5,5'-dithio-bis(2-nitrobenzoic acid) (DTNB), sodium nitroprusside dehydrate (SNP), linoleic acid, L-ascorbic acid and sulphanilamide, acetylcholinesterase (AChE) from electric eel (type VI-s, lyophilized powder), acetylthiocholine iodide (ATCI), butyrylcholinesterase (BChE) from equine serum (lyophilized powder), $S$-butyrylthiocholine chloride (BTCC), $\alpha$-glucosidase (type I from baker's yeast) and 4-nitrophenyl $\alpha$-D-glucopyranoside (PNP-G) were purchased from Sigma (St. Louis, MO, USA). Trizma hydrochloride (Tris-HCl) and bovine serum albumin (BSA) were provided from Sigma-Aldrich (Steinheim, Germany).

Chlorogenic acid, caffeic acid, cynarin, kaempferol and rutin used as standards were purchased from Extrasynthese (Genay, France). HPLC-grade methanol and formic acid were acquired from Merck (Darmstadt, Germany). Water was deionized using a Milli-Q water purification system (Millipore, Bedford, MA, USA). 


\subsection{Plant Material}

In this study, dried foliar tissues from fourteen landraces of Smallanthus sonchifolius (named PER01-PER11, ECU41, ECU43 and ECU44, as assigned in a previous study [53]) were analyzed to investigate the phenolic content and biological properties. A voucher specimen for each landrace (numbered CZU-ECU41, ECU43, ECU44 and PERn-11, where $n$ is the number of the landrace as named above) is deposited in herbarium of the Faculty of Tropical Agriculture, Czech University of Agriculture, Prague. The plant material has been acquired since 1993 from different parts of the world and selected for their morphological traits [54]. They are maintained and cultivated under the field conditions of trial plots at the Faculty of Tropical AgriSciences (FTA, former Institute of Tropics and Subtropics), Czech University of Life Sciences Prague (CULS) [53].

\subsection{Preparation of Plant Extracts}

Dried leaves of all yacon landraces were coarsely powered by mortar and pestle and extracted by maceration technique with frequent agitation for three times with the same solvent (ratio 1:8 w/v). Solvents with increasing polarity, $n$-hexane, chloroform $\left(\mathrm{CHCl}_{3}\right)$, mixture $\mathrm{CHCl}_{3}:$ methanol $(\mathrm{MeOH})$ in ratio 9:1 and $\mathrm{MeOH}$ were used. The mixtures were filtered by cellulose filter paper $(17-25 \mu \mathrm{m})$ and the combined liquids were evaporated to dryness under reduced pressure by using rotary evaporator. The extracts were kept in the dark at room temperature until use. The percentage of yield extracts was calculated as $\%$ yield $=($ Weight of dried extract/Initial weight of dried foliar tissue $) \times 100$.

\subsection{Total Polyphenol, Tannin and Flavonoid Content}

\subsubsection{Total Polyphenol Content}

The total phenolic (TPC) content was determined by Folin-Ciocalteu reagent [55]. Briefly, $75 \mu \mathrm{L}$ of diluted extract and $425 \mu \mathrm{L}$ of distilled water was added to $500 \mu \mathrm{L}$ Folin-Ciocalteu reagent and $500 \mu \mathrm{L}$ of $\mathrm{Na}_{2} \mathrm{CO}_{3}(10 \% \mathrm{w} / \mathrm{v})$. The mixture was mixed and incubated for $1 \mathrm{~h}$ in the dark at room temperature. After incubation, the absorbance was measured at $723 \mathrm{~nm}$ using a UV-Vis spectrophotometer (DU 640 Spectrophotometer, Beckman, Brea, CA, USA). The total phenolic content was expressed as mg gallic acid equivalent (GAE)/gof extract.

\subsubsection{Total Tannin Content}

To $250 \mu \mathrm{L}$ of different concentrations of extract $(10 \mathrm{mg} / \mathrm{mL}), 500 \mu \mathrm{L}$ of bovine serum albumin solution in $0.2 \mathrm{~mol} / \mathrm{L}$ acetic buffer, $\mathrm{pH} 5.0$ with $0.17 \mathrm{~mol} / \mathrm{L} \mathrm{NaCl}(1 \mathrm{mg} / \mathrm{mL})$ was added and mixed carefully [25]. After $15 \mathrm{~min}$, the samples were centrifuged at $5000 \mathrm{~g}$ for $15 \mathrm{~min}$. The supernatant was removed, and the pellet dissolved in $1 \mathrm{~mL}$ of aqueous solution containing $1 \% \mathrm{SDS}$ and $4 \%$ triethanolamine. Then, $250 \mu \mathrm{L}$ of $0.01 \mathrm{~mol} / \mathrm{L} \mathrm{FeCl}_{3}$ in $0.01 \mathrm{~mol} / \mathrm{L} \mathrm{HCl}$ was added. After $30 \mathrm{~min}$ the absorbance was recorded at $510 \mathrm{~nm}$. Results were expressed as $\mathrm{mg}$ of tannic acid equivalent/g of extract (mg TAE/g of extract). 


\subsubsection{Total Flavonid Content}

An aliquot $(150 \mu \mathrm{L})$ of extract at $10.00 \mathrm{mg} / \mathrm{mL}$ was added to $45 \mu \mathrm{L}$ of $5 \% \mathrm{NaNO}_{3}$ into microcentrifuge tube. After $5 \mathrm{~min}, 90 \mu \mathrm{L}$ of $1 \% \mathrm{AlCl}_{3}$ was added and at the 6th minute, $300 \mu \mathrm{L}$ of $1 \mathrm{M} \mathrm{NaOH}$ solution was added and the total volume was made up to $1.5 \mathrm{~mL}$ with distilled water. The solution was mixed well and the absorbance was measured against reagent blank at $510 \mathrm{~nm}$ after $10 \mathrm{~min}$ of incubation at room temperature [56]. Quercetin was used as standard to plot the calibration curve. The total flavonoid content was expressed as $\mathrm{mg}$ of quercetin equivalent/g of extract (mg QE/g of extract).

\subsection{Biological Activity}

\subsubsection{Reducing Power}

Reducing power of the extracts was determined by ferric reducing ability power test (FRAP) [57]. The stock solution included $300 \mathrm{mM}$ acetate buffer, $\mathrm{pH}$ 3.6, $10 \mathrm{mM}$ TPTZ (2,4,6-tripyridyl-s-triazine) solution in $40 \mathrm{mM} \mathrm{HCl}$, and $20 \mathrm{mM} \mathrm{FeCl}_{3} \cdot 6 \mathrm{H}_{2} \mathrm{O}$ solution. The working solution was prepared by mixing acetate buffer, TPTZ and $\mathrm{FeCl}_{3} \cdot 6 \mathrm{H}_{2} \mathrm{O}(10: 1: 1)$. Plant extracts $(150 \mu \mathrm{L})$ were allowed to react with $2850 \mu \mathrm{L}$ of the FRAP solution for $40 \mathrm{~min}$ at $37{ }^{\circ} \mathrm{C}$. Readings of the colored product (ferrous tripyridyltriazine complex) were taken at $593 \mathrm{~nm}$. Trolox was used as standard and results were expressed in mg of trolox equivalent (TE)/g of dried sample.

\subsubsection{DPPH Scavenging Activity}

Radical-scavenging activity was evaluated by using DPPH test [58]. Briefly, $80 \mu \mathrm{L}$ of plant extracts were added to $1420 \mu \mathrm{L}$ of DPPH (2,2-diphenyl-1-picrylhydrazyl) solution in a microcentrifuge tubes and left in the dark. The absorbance was monitored every $30 \mathrm{~min}$ until $90 \mathrm{~min}$ at $515 \mathrm{~nm}$ by using spectrophotometer (UV 640 Spectrophotometer). Results were expressed as IC $_{50}$ and compared with the Trolox, used as standard.

\subsubsection{Nitric Oxide ( NO) Radical Scavenging Activity}

The capacity to scavenge $\mathrm{NO}$ was evaluated spectrophotometrically in a Multiskan Ascent plate reader (Thermo Electron Corporation, Shanghai, China), according to a previously described procedure [33], with different concentration of extracts. $\mathrm{NO}$ was generated in vitro from sodium nitroprussiate dehydrate (SNP) and measured by the Griess reaction. SNP solution $(6 \mathrm{mg} / \mathrm{mL})$ was prepared in phosphate buffer $\left(\mathrm{KH}_{2} \mathrm{PO}_{4} 100 \mathrm{mM}, \mathrm{pH}\right.$ 7.4) and mixed with the same volume $(100 \mu \mathrm{L})$ of different concentrations of extracts, in a 96-wells plate. The mixture was further incubated at room temperature for $1 \mathrm{~h}$ under light. After that, $100 \mu \mathrm{L}$ of Griess reagent $(1: 1$ mixture $(v / v)$ of $1 \%$ sulfanilamide and $0.1 \% N-\left(1\right.$-naphthyl) ethylenediamine in $\left.2 \% \mathrm{H}_{3} \mathrm{PO}_{4}\right)$ was added and the mixture was further incubated for $10 \mathrm{~min}$ in the dark. The absorbance was read at $560 \mathrm{~nm}$. Results were expressed as $\mathrm{IC}_{50}$ and ascorbic acid was used as positive control. 


\subsubsection{Superoxide Radical $\left(\mathrm{O}_{2}{ }^{--}\right)$Scavenging Activity}

The effect of the extract on the superoxide radical-induced reduction of NBT was monitored spectrophotometrically in a Multiskan Ascent plate reader (Thermo Electron Corporation), in kinetic function, at $560 \mathrm{~nm}$. Superoxide radicals were generated by the phenazine methosulfate- $\beta$-nicotinamide adenine dinucleotide (PMS-NADH) system, as previously reported [33]. Several dilutions of sample $(50 \mu \mathrm{L})$ or phosphate buffer as control, NADH $(50 \mu \mathrm{L})$ and NBT $(150 \mu \mathrm{L})$ were put in the 96 -well plate. The reaction was started by adding PMS $(50 \mu \mathrm{L})$ to the mixture. The assay was conducted at room temperature at $560 \mathrm{~nm}$ for $2 \mathrm{~min}$. For each extract, five different concentrations were tested. Results were expressed as $\mathrm{IC}_{50}$ and ascorbic acid was used as positive control.

\subsubsection{Lipid Peroxidation Inhibition (LOO`Radical)}

Lipid peroxyl radical (LOO`) was generated as proposed by Ferreres et al. [59] with slight modifications. The reaction mixture contained $250 \mu \mathrm{L}$ of $5 \mathrm{mM}$ linoleic acid, $150 \mu \mathrm{L}$ of Tris- $\mathrm{HCl}$ (100 mM, pH 7.5), $50 \mu \mathrm{L}$ of $4 \mathrm{mM} \mathrm{FeSO}_{4} \cdot 7 \mathrm{H}_{2} \mathrm{O}$ and $50 \mu \mathrm{L}$ of serial dilutions of extracts prepared in distilled $\mathrm{H}_{2} \mathrm{O}$. Linoleic acid peroxidation was initiated by the addition of $50 \mu \mathrm{L}$ of $5 \mathrm{mM}$ ascorbic acid, and the mixture was immediately incubated for $1 \mathrm{~h}$ at $37^{\circ} \mathrm{C}$. After the incubation period, $3 \mathrm{~mL}$ of ethanol was added to each test tube. The mixtures were vortexed and the absorbance was immediately measured at $233 \mathrm{~nm}$ in a Helios $\alpha$ (Unicam) spectrophotometer, at room temperature. Results were expressed as $\mathrm{IC}_{50}$ and BHT was used as positive control.

\subsection{6. $\alpha$-Amylase and $\alpha$-Glucosidase Inhibitory Activity}

Different concentration of each sample extract $(100 \mu \mathrm{L})$ and $100 \mu \mathrm{L}$ of $0.02 \mathrm{M}$ sodium phosphate buffer ( $\mathrm{pH} 6.9$ with $0.006 \mathrm{M} \mathrm{NaCl})$ containing $\alpha$-amylase solution $(0.5 \mathrm{mg} / \mathrm{mL})$ were incubated at $25{ }^{\circ} \mathrm{C}$ for $10 \mathrm{~min}$. After pre-incubation, $100 \mu \mathrm{L}$ of a $1 \%$ starch solution in sodium phosphate buffer was added to each tube at timed intervals. The reaction mixtures were then incubated at $25{ }^{\circ} \mathrm{C}$ for $10 \mathrm{~min}$. The reaction was stopped with $200 \mu \mathrm{L}$ of dinitrosalicylic acid color reagent. The test tubes were then incubated in a boiling water bath for $5 \mathrm{~min}$ and cooled to room temperature. The reaction mixture was then diluted after adding $3 \mathrm{~mL}$ of distilled water, and absorbance was measured at $540 \mathrm{~nm}$. The absorbance of blanks (enzyme solution was added during the boiling) and a control (buffer in place of sample extract) were recorded [60]. Analyses were performed in triplicate and the final extract absorbance $(540 \mathrm{~nm})$ was obtained by subtracting its corresponding sample blank reading.

The effect on $\alpha$-glucosidase was assessed in 96-well plates, using a procedure previously reported [61]. Briefly, each well contained $2.5 \mathrm{mM}$ PNP-G $(100 \mu \mathrm{L})$ in phosphate buffer $\mathrm{pH} 7.0$ $(150 \mu \mathrm{L})$ and methanol extract at different concentrations $(50 \mu \mathrm{L})$. The reaction was initiated by the addition of $0.28 \mathrm{U} / \mathrm{mL}$ enzyme $(20 \mu \mathrm{L})$ and the plates were incubated at $37{ }^{\circ} \mathrm{C}$ for $10 \mathrm{~min}$. The absorbance at $400 \mathrm{~nm}$ was measured in a Multiskan Ascent plate reader (Thermo Electron Corporation). Results were expressed as $\mathrm{IC}_{50}$ calculated from three independent tests, performed in triplicate and acarbose was used as positive control in both assays. 


\subsubsection{Acetylcholinesterase (AChE) and Butyrylcholinesterase (BChE) Inhibitory Activity}

The inhibition of AChE activity was determined based on Ellman's method, as previously reported [61]. In this assay, $25 \mu \mathrm{L}$ of acetylthiocholine iodide $(15 \mathrm{mM}), 125 \mu \mathrm{L}$ of DTNB (3 $\mathrm{mM})$, $25 \mu \mathrm{L}$ of buffer B (50mM Tris-HCl, $\mathrm{pH} 8$ containing $0.1 \% \mathrm{BSA})$ and $50 \mu \mathrm{L}$ of each test extract solution at the different concentrations were mixed. The mixture was monitored at $405 \mathrm{~nm}$. The reaction was started by adding $25 \mu \mathrm{L}$ of $0.44 \mathrm{U} / \mathrm{mL}$ AChE. The absorbance was measured at $405 \mathrm{~nm}$ and the rates of reactions were calculated by Ascent Software version 2.6 (Thermo Labsystems Oy, Vantaa, Finland). The BChE inhibition assay was performed in a similar way [62] using $25 \mu \mathrm{L}$ of $15 \mathrm{mM}$ butyrylthiocholine chloride as substrate and $0.1 \mathrm{U} / \mathrm{mL}$ of $\mathrm{BChE}$ as enzyme. Three independent assays were performed in triplicate at different concentrations.

\subsection{HPLC-DAD Qualitative and Quantitative Analyses}

Redissolved methanol extract $(50 \mathrm{mg} / \mathrm{mL})$ was analyzed on an analytical HPLC-DAD unit (Gilson) using a Luna C18 column $(250 \times 4.6 \mathrm{~mm}, 5 \mu \mathrm{m}$ particle size; Phenomenex, Macclesfield, UK). The mobile phase consisted of two solvents: water-formic acid (5\%) (A) and methanol (B), starting with $5 \% \mathrm{~B}$ and using a gradient to obtain $15 \% \mathrm{~B}$ at $3 \mathrm{~min}, 25 \% \mathrm{~B}$ at $13 \mathrm{~min}, 30 \% \mathrm{~B}$ at $25 \mathrm{~min}, 35 \% \mathrm{~B}$ at $35 \mathrm{~min}, 45 \% \mathrm{~B}$ at $42 \mathrm{~min}, 55 \% \mathrm{~B}$ at $47 \mathrm{~min}, 75 \% \mathrm{~B}$ at $56 \mathrm{~min}$ and $100 \% \mathrm{~B}$ at $60 \mathrm{~min}$. The flow rate was $0.9 \mathrm{~mL} / \mathrm{min}$. Spectral data from all peaks were collected in the range of $200-400 \mathrm{~nm}$, and chromatograms were recorded at $320 \mathrm{~nm}$ for hydroxycinnamic acids and at $350 \mathrm{~nm}$ for flavonoids. The data were processed on Unipoint System software (Gilson Medical Electronics, Villiers le Bel, France).

Whenever available, reference standards of phenolics were used to substantiate the identification of the peaks. Phenolic compounds, which were not available as standard reference materials were tentatively identified according to the literature [62] and confirmed by matching their retention time and UV spectra using the same chromatographic condition of a previous work conducted by our team [63].

Phenolic compounds quantification was achieved by the absorbance recorded in the chromatograms relative to external calibration standards.

Phenolic acid derivatives $(320 \mathrm{~nm})$ were quantified as caffeic acid, 1,5-di-O-caffeoylquinic, 3,5-di- $O$-dicaffeoylquinic acid and 4,5-di- $O$-caffeoylquinic acid were quantified as cynarin (1,3-O-dicaffeoylquinic acid, $320 \mathrm{~nm})$, flavonoid derivatives were quantified as kaempferol $(350 \mathrm{~nm})$. The other compounds were quantified as themselves.

\subsection{Statistical Analysis}

A minimum of three independent experiments were carried out unless otherwise specified. Results are presented as mean \pm standard deviation (Mean \pm SD) by using Microsoft Excel. Value of $p<0.05$ was considered statistically significant. Calibration curves of the standards were considered as linear if $R^{2}>0.99$. The comparison among all chemical methods used to investigate antioxidant activity was used to determine relative antioxidant capacity index (RACI). Pearson's correlation coefficient was used to determine the relation between the variables by using Microsoft Excel. For more detailed insight in the relations between the variables, results were submitted to multivariate principal component analysis (PCA) using XLSTAT Version 2015.1 (Addinsoft Inc., New York, NY, USA). 


\section{Conclusions}

This study supports the traditional use of $S$. sonchifolius to treat several ailments. Experimental studies of methanol extract of leaf tissue exhibited considerable antidiabetic and antioxidant activities. Significant differences between individual landraces were found and the results of this study showed that yacon could have a possible application in the pharmaceutical and nutraceutical fields, being a rich source of many bioactive compounds. The selection and propagation of specific landraces, supported by appropriate extraction procedure, would ensure greater concentration of active components and, consequently, a higher biological activity.

Our approach used some assays regarding reactive species and enzymes with biological significance (e.g., nitric oxide and superoxide anion radical scavenging activity and the cholinesterase inhibition), and results are reported here for the first time. Moreover, our HPLC protocol allowed the identification of 1,5-di-O-caffeoylquinic acid, which was not previously reported in yacon leaves.

The specific compounds responsible for yacon biological activities need to be found and further investigations for the most active compounds will be done in the near future.

\section{Acknowledgments}

Daniela Russo would like to thank Paula B. Andrade, Patrícia Valentão and Rui Gonçalves from University of Porto (Portugal) for their valuable assistance and support during her experience abroad.

This work was supported by Projects No 20135002 and 20155011 of University Internal Grant Agency, Czech University of Life Sciences Prague.

\section{Author Contributions}

Luigi Milella, Paula B. Andrade and Patrícia Valentão contributed to conceived and design the experiments; Daniela Russo performed the experiments; Luigi Milella, Patrícia Valentão, Paula B. Andrade and Eloy C. Fernandez contributed reagents/materials/analysis tools; Luigi Milella and Daniela Russo analysed data and wrote the manuscript. All authors read and approved the final manuscript.

\section{Conflicts of Interest}

The authors declare no conflict of interest.

\section{References}

1. Fernández, E.C.; Viehmannová, I.; Lachman, J.; Milella, L. Yacon (Smallanthus sonchifolius (Poeppig \& Endlicher) H. Robinson): A new crop in the central europe. Plant Soil Environ. 2006, 52, 564-570.

2. Milella, L.; Salava, J.; Martelli, G.; Greco, I.; Cusimani, E.F.; Viehmannová, I. Genetic diversity between yacon landraces from different countries based on random amplified polymorphic DNAs. Czech J. Genet. Plant Breed. 2005, 41, 73-78.

3. Ojansivu, I.; Ferreira, C.L.; Salminen, S. Yacon, a new source of prebiotic oligosaccharides with a history of safe use. Trends Food Sci. Technol. 2011, 22, 40-46. 
4. Fernandez, E.C.; Rajchl, A.; Lachman, J.; Cizkova, H.; Kvasnicka, F.; Kotikova, Z.; Milella, L.; Voldrich, M. Impact of yacon landraces cultivated in the czech republic and their ploidy on the short- and long-chain fructooligosaccharides content in tuberous roots. LWT Food Sci. Technol. 2013, 54, 80-86.

5. Aybar, M.J.; Sanchez Riera, A.N.; Grau, A.; Sanchez, S.S. Hypoglycemic effect of the water extract of Smallantus sonchifolius (yacon) leaves in normal and diabetic rats. J. Ethnopharmacol. 2001, 74, 125-132.

6. Xiang, Z.; He, F.; Kang, T.G.; Dou, D.Q.; Gai, K.; Shi, Y.Y.; Young-Ho, K.; Dong, F. Anti-diabetes constituents in leaves of Smallanthus sonchifolius. Nat. Prod. Commun. 2010, 5, 95-98.

7. Lachman, J.; Fernández, E.C.; Orsák, M. Yacon (Smallanthus sonchifolia (Poepp. et Endl.) H. Robinson) chemical composition and use-A review. Plant Soil Environ. 2003, 49, 283-290.

8. Schorr, K.; da Costa, F.B. Quantitative determination of enhydrin in leaf rinse extracts and in glandular trichomes of Smallanthus sonchifolius (asteraceae) by reversed-phase high-performance liquid chromatography. Phytochem. Anal. 2005, 16, 161-165.

9. Lebeda, A.; Dolezalova, I.; Valentova, K.; Dziechciarkova, M.; Greplova, M.; Opatova, H.; Ulrichova, J. Biological and chemical variability of maca and yacon. Chem. Listy 2003, 97, 548-556.

10. Valentova, K.; Cvak, L.; Muck, A.; Ulrichova, J.; Simanek, V. Antioxidant activity of extracts from the leaves of Smallanthus sonchifolius. Eur. J. Nutr. 2003, 42, 61-66.

11. Valentova, K.; Sersen, F.; Ulrichova, J. Radical scavenging and anti-lipoperoxidative activities of Smallanthus sonchifolius leaf extracts. J. Agric.Food Chem. 2005, 53, 5577-5582.

12. Simonovska, B.; Vovk, I.; Andrensek, S.; Valentova, K.; Ulrichova, J. Investigation of phenolic acids in yacon (Smallanthus sonchifolius) leaves and tubers. J. Chromatogr. A 2003, 1016, 89-98.

13. Lin, F.Q.; Hasegawa, M.; Kodama, O. Purification and identification of antimicrobial sesquiterpene lactones from yacon (Smallanthus sonchifolius) leaves. Biosci. Biotechnol. Biochem. 2003, 67, 2154-2159.

14. Hostettmann, K.; Borloz. A.U.; Marston, A. Natural product inhibitors of acetylcholinesterase. Curr. Org. Chem. 2006, 10, 825-847.

15. Mukherjee, P.K.; Kumar, V.; Mal, M.; Houghton, P.J. Acetylcholinesterase inhibitors from plants. Phytomedicine 2007, 14, 289-300.

16. Bakirel, T.; Bakirel, U.; Keles, O.U.; Ulgen, S.G.; Yardibi, H. In vivo assessment of antidiabetic and antioxidant activities of rosemary (Rosmarinus officinalis) in alloxan-diabetic rabbits. J. Ethnopharmacol. 2008, 116, 64-73.

17. García-Fontana, B.; Morales-Santana, S.; Longobardo, V.; Reyes-García, R.; Rozas-Moreno, P.; García-Salcedo, J.; Muñoz-Torres, M. Relationship between proinflammatory and antioxidant proteins with the severity of cardiovascular disease in type 2 diabetes mellitus. Int. J. Mol. Sci. 2015, 16, 9469-9483.

18. Luo, Q.; Cai, Y.; Yan, J.; Sun, M.; Corke, H. Hypoglycemic and hypolipidemic effects and antioxidant activity of fruit extracts from Lycium barbarum. Life Sci. 2004, 76, 137-149.

19. Gupta, R.; Gigras, P.; Mohapatra, H.; Goswami, V.K.; Chauhan, B. Microbial $\alpha$-amylases: A biotechnological perspective. Process Biochem. 2003, 38, 1599-1616. 
20. Anam, K.; Widharna, R.M.; Kusrini, D. $\alpha$-Glucosidase inhibitor of Terminalia species. Int. J. Pharmacol. 2009, 5, 277-280.

21. Fred-Jaiyesimi, A.; Kio, A.; Richard, W. $\alpha$-Amylase inhibitory effect of 3 $\beta$-olean-12-en-3-yl (9Z)hexadec-9-enoate isolated from Spondias mombin leaf. Food Chem. 2009, 116, 285-288.

22. Valko, M.; Leibfritz, D.; Moncol, J.; Cronin, M.T.D.; Mazur, M.; Telser, J. Free radicals and antioxidants in normal physiological functions and human disease. Int. J. Biochem. Cell B 2007, $39,44-84$.

23. Scherer, R.; Godoy, H.T. Effects of extraction methods of phenolic compounds from Xanthium strumarium L. and their antioxidant activity. Rev. Bras. Plant. Med. 2014, 16, 41-46.

24. Naczk, M.; Pegg, R.B.; Amarowicz, R. Protein-precipitating capacity of bearberry-leaf (Arctostaphylos uva-ursi L. Sprengel) polyphenolics. Food Chem. 2011, 124, 1507-1513.

25. Hagerman, A.E.; Butler, L.G. Protein precipitation method for the quantitative determination of tannins. J. Agric. Food Chem. 1978, 26, 809-812.

26. Rajanandh, M.G.; Kavitha, J. Quantitative estimation of $\beta$-sitosterol, total phenolic and flavonoid compounds in the leaves of Moringa oleifera. Int. J. PharmTech Res. 2010, 2, 1409-1414.

27. Edewor, T.I.; Akpor, O.B.; Owa, S.O. Quantification of the total phenolic and flavonoid contents, and antibacterial activity of Dioclea reflexa. Int. J. PharmTech Res. 2014, 6, 1875-1880.

28. Hagerman, A.E. Radial diffusion method for determining tannin in plant extracts. J. Chem. Ecol. 1987, 13, 437-449.

29. Condelli, N.; Caruso, M.C.; Galgano, F.; Russo, D.; Milella, L.; Favati, F. Prediction of the antioxidant activity of extra virgin olive oils produced in the mediterranean area. Food Chem 2015, 177, 233-239.

30. Jimenez-Escrig, A.; Jimenez-Jimenez, I.; Sanchez-Moreno, C.; Saura-Calixto, F. Evaluation of free radical scavenging of dietary carotenoids by the stable radical 2,2-diphenyl-1-picrylhydrazyl. J. Sci. Food Agric. 2000, 80, 1686-1690.

31. Brune, B. Nitric oxide: No apoptosis or turning it on? Cell Death Differ. 2003, 10, 864-869.

32. Marcocci, L.; Maguire, J.J.; Droy-Lefaix, M.T.; Packer, L. The nitric oxide-scavenging properties of Ginkgo biloba extract EGb 761. Biochem. Biophys. Res. Commun. 1994, 201, 748-755.

33. Ferreres, F.; Gil-Izquierdo, A.; Vinholes, J.; Silva, S.T.; Valentão, P.; Andrade, P.B. Bauhinia forficata link authenticity using flavonoids profile: Relation with their biological properties. Food Chem. 2012, 134, 894-904.

34. Kussmaul, L.; Hirst, J. The mechanism of superoxide production by NADH:ubiquinone oxidoreductase (complex I) from bovine heart mitochondria. Proc. Natl. Acad. Sci. USA 2006, 103, 7607-7612.

35. De Zwart, L.L.; Meerman, J.H.; Commandeur, J.N.; Vermeulen, N.P. Biomarkers of free radical damage applications in experimental animals and in humans. Free Radic. Biol. Med. 1999, 26, 202-226.

36. Gutteridge, J.M.; Halliwell, B. The measurement and mechanism of lipid peroxidation in biological systems. Trends Biochem. Sci. 1990, 15, 129-135.

37. Halliwell, B.; Chirico, S. Lipid peroxidation: Its mechanism, measurement, and significance. Am. J. Clin. Nutr. 1993, 57, 715S-724S. 
38. Corongiu, F.P.; Banni, S. Detection of conjugated dienes by second derivative ultraviolet spectrophotometry. Methods Enzymol. 1994, 233, 303-310.

39. Suba, V.; Murugesan, T.; Arunachalam, G.; Mandal, S.C.; Saha, B.P. Antidiabetic potential of Barleria lupulina extract in rats. Phytomedicine 2004, 11, 202-205.

40. Ahmad, S.; Ullah, F.; Ayaz, M.; Sadiq, A.; Imran, M. Antioxidant and anticholinesterase investigations of Rumex hastatus d. Don: Potential effectiveness in oxidative stress and neurological disorders. Biol. Res. 2015, 48, 20.

41. Ellman, G.L.; Courtney, K.D.; Andres, V., Jr.; Feather-Stone, R.M. A new and rapid colorimetric determination of acetylcholinesterase activity. Biochem. Pharmacol. 1961, 7, 88-95.

42. Genta, S.B.; Cabrera, W.M.; Mercado, M.I.; Grau, A.; Catalan, C.A.; Sanchez, S.S. Hypoglycemic activity of leaf organic extracts from Smallanthus sonchifolius: Constituents of the most active fractions. Chem. Biol. Interact. 2010, 185, 143-152.

43. Yang, H.Y.; Du, G.; Cheng, X.M.; Yang, X.X.; Liu, M.H.; Dai, Y. Determination of rutin and quercetin in extraction of leaves of yacon with ethanol by using HPLC. Food Res. Dev. 2008, 9 , $119-121$.

44. Oliveira, R.B.; Chagas-Paula, D.A.; Secatto, A.; Gasparoto, T.H.; Faccioli, L.H.; Campanelli, A.P.; da Costa, F.B. Topical anti-infl ammatory activity of yacon leaf extracts. Res. Bras. Pharmacogn. 2013, 23, 497-505.

45. Russo, D.; Malafronte, N.; Frescura, D.; Imbrenda, G.; Faraone, I.; Milella, L.; Fernandez, E.; de Tommasi, N. Antioxidant activities and qualiquantitative analysis of different Smallanthus sonchifolius ((Poepp. and Endl.) H. Robinson) landrace extracts. Nat. Prod. Res. 2014, 23, 1-5.

46. Valentão, P.; Fernandes, E.; Carvalho, F.; Andrade, P.B.; Seabra, R.M.; Bastos, M.L. Antioxidative properties of cardoon (Cynara cardunculus L.) infusion against superoxide radical, hydroxyl radical, and hypochlorous acid. J. Agric. Food Chem. 2002, 50, 4989-4993.

47. Yan, X.; Suzuki, M.; Ohnishi-Kameyama, M.; Sada, Y.; Nakanishi, T.; Nagata, T. Extraction and identification of antioxidants in the roots of yacon (Smallanthus sonchifolius). J. Agric. Food Chem. 1999, 47, 4711-4713.

48. Sun, T.; Tanumihardjo, S.A. An integrated approach to evaluate food antioxidant capacity. J. Food Sci. 2007, 72, 159-165.

49. Fernandes, F.; Ramalhosa, E.; Pires, P.; Verdial, J.; Valentão, P.; Andrade, P.A.; Bento, A.; Pereira, J.A. Vitis vinifera leaves towards bioactivity. Ind. Crop. Prod. 2013, 43, 434-440.

50. Lim, Y.J.; Oh, C.S.; Park, Y.D.; Eom, S.H.; Kim, D.O.; Kim, U.J.; Cho, Y.S. Physiological components of kiwifruits with in vitro antioxidant and acetylcholinesterase inhibitory activities. Food Sci. Biotechnol. 2014, 23, 943-949.

51. Panceri, C.P.; Gomes, T.M.; de Gois, J.S.; Borges, D.L.G.; Bordignon-Luiz, M.T. Effect of dehydration process on mineral content, phenolic compounds and antioxidant activity of cabernet sauvignon and merlot grapes. Food Res. Int. 2013, 54, 1343-1350.

52. Oszmiański, J.; Nowicka, P.; Teleszko, M.; Wojdyło, A.; Cebulak, T.; Oklejewicz, K. Analysis of phenolic compounds and antioxidant activity in wild blackberry fruits. Int. J. Mol. Sci. 2015, 16, 14540-14553. 
53. Svobodova, E.; Dvorakova, Z.; Cepkova, P.H.; Viehmannova, I.; Havlickova, L.; Cusimamani, E.F.; Russo, D.; Zela, G.M. Genetic diversity of yacon (Smallanthus sonchifolius (Poepp. \& Endl.) H. Robinson) and its wild relatives as revealed by ISSR markers. Biochem. Syst. Ecol. 2013, 50, 383-389.

54. Milella, L.; Martelli, G.; Salava, J.; Fernandez, E.; Ovesna, J.; Greco, I. Total phenolic content, RAPDs, AFLPs and morphological traits for the analysis of variability in Smallanthus sonchifolius. Genet. Resour. Crop Evol. 2011, 58, 545-551.

55. Milella, L.; Caruso, M.; Galgano, F.; Favati, F.; Padula, M.C.; Martelli, G. Role of the cultivar in choosing clementine fruits with a high level of health-promoting compounds. J. Agric. Food Chem. 2011, 59, 5293-5298.

56. Lobo, R.; Sodde, V.; Dashora, N.; Gupta N.; Prabhu, K. Quantification of flavonoid and phenol content from Macrosolen parasiticus (L.) Danser. J. Nat. Prod. Plant Resour. 2011, 11, 96-99.

57. Russo, D.; Bonomo, M.G.; Salzano, G.; Martelli, G.; Milella, L. Nutraceutical properties of Citrus clementina juices. Pharmacologyonline 2012, 1, 84-93.

58. Milella, L.; Bader, A.; de Tommasi, N.; Russo, D.; Braca, A. Antioxidant and free radical-scavenging activity of constituents from two scorzonera species. Food Chem. 2014, 160, 298-304.

59. Ferreres, F.; Lopes, G.; Gil-Izquierdo, A.; Andrade, P.B.; Sousa, C.; Mouga, T.; Valentão, P. Phlorotannin extracts from fucales characterised by HPLC-DAD-ESI-MS ${ }^{n}$ : Approaches to hyaluronidase inhibitory capacity and antioxidant properties. Mar. Drugs 2012, 10, 2766-2781.

60. Ranilla, L.G.; Kwon, Y.I.; Apostolidis, E.; Shetty, K. Phenolic compounds, antioxidant activity and in vitro inhibitory potential against key enzymes relevant for hyperglycemia and hypertension of commonly used medicinal plants, herbs and spices in Latin America. Bioresour. Technol. 2010, 101, 4676-4689.

61. Vinholes, J.; Grosso, C.; Andrade, P.B.; Gil-Izquierdo, A.; Valentão, P.; de Pinho, P.G.; Ferreres, F. In vitro studies to assess the antidiabetic, anti-cholinesterase and antioxidante potential of Spergularia rubra. Food Chem. 2011, 129, 454-462.

62. Takenaka, M.; Yan, X.; Ono, H.; Yoshida, M.; Nagata, T.; Nakanishi, T. Caffeic acid derivatives in the roots of yacon (Smallanthus sonchifolius). J. Agric. Food Chem. 2003, 51, 793-796.

63. Seabra, R.M.; Andrade, P.B.; Valentão, P.; Fernandes, E.; Carvalho, F.; Bastos, M.L. Antioxidant compounds extracted from several plant materials. In Biomaterials from Aquatic and Terrestrial Organisms; Fingerman, M., Nagabhushanam R., Eds; Science Publishers: Enfield, NH, USA, 2006; pp. 115-174.

(C) 2015 by the authors; licensee MDPI, Basel, Switzerland. This article is an open access article distributed under the terms and conditions of the Creative Commons Attribution license (http://creativecommons.org/licenses/by/4.0/). 